\title{
Simulasi Implementasi Intrusion Prevention System (IPS) Pada Router Mikrotik
}

\author{
Yudhi Arta $^{1}$, Abdul Syukur ${ }^{2}$, Roni Kharisma ${ }^{3}$ \\ ${ }^{1,2,3}$ Program Studi Teknik Informatika, Fakultas Teknik, Universitas Islam Riau \\ 1yudhiarta@eng.uir.ac.id, ${ }^{2}$ abdulsyukur@eng.uir.ac.id, ${ }^{3}$ roni100194@gmail.com
}

\begin{abstract}
Computer network security is part of a system that is critical to maintaining the validity and integrity of data and ensuring the availability of services for its users. Current network intrusion detection systems are generally able to detect attacks but are unable to take further action. But on the one hand humans are very dependent with the information system. This is what causes the statistics of network security incidents continue to increase sharply from year to year. This is due to the very poor people's concern for the network security system. Therefore a system that can help network administrator to be used as monitor network traffic with Intrusion Prevention System (IPS) which is a combination of facility blocking capabilities of Firewall.
\end{abstract}

Keywords : firewall, Intrusion Prevention System, router mikrotik.

\begin{abstract}
Abstrak
Keamanan jaringan komputer merupakan bagian dari sebuah sistem yang sangat penting untuk menjaga validitas dan integritas data serta menjamin ketersediaan layanan bagi penggunanya. Sistem deteksi penyusup jaringan yang ada saat ini umumnya mampu mendeteksi berbagai serangan tetapi tidak mampu mengambil tindakan lebih lanjut. Namun disatu sisi manusia sudah sangat tergantung dengan sistem informasi. Hal itu yang menyebabkan statistik insiden keamanan jaringan terus meningkat tajam dari tahun ke tahun. Ini disebabkan karena kepedulian masyarakat yang sangat kurang terhadap sistem keamanan jaringan. Maka dari itu dibutuhkan sebuah sistem yang dapat membantu network administrator untuk digunakan sebagai monitor trafik jaringan dengan Intrusion Prevention System (IPS) yang merupakan kombinasi antara fasilitas blocking capabilities dari Firewall.
\end{abstract}

Kata kunci: firewall, Intrusion Prevention System, router mikrotik.

\section{PENDAHULUAN}

Keamanan jaringan komputer merupakan bagian dari sebuah sistem yang sangat penting untuk menjaga validitas dan integritas data serta menjamin ketersediaan layanan bagi penggunanya. Sistem deteksi penyusup jaringan yang ada saat ini umumnya mampu mendeteksi berbagai serangan tetapi tidak mampu mengambil tindakan lebih lanjut.[1][2][3][4]

Pada sisi lain timbul masalah serius yaitu faktor keamanannya, namun disatu sisi manusia sudah sangat tergantung dengan sistem informasi. Hal itu yang menyebabkan statistik insiden keamanan jaringan terus meningkat tajam dari tahun ke tahun. 
Dalam perkembangan teknologi sekarang yang sudah semakin pesat, kebutuhan akan keamanan jaringan tentunya meningkat seiring dengan berkembangnya ilmu pengetahuan tentang masalah hacking dan cracking yang bersifat free dan ada pula yang dikomersilkan. Kemudian dari sisi software pendukung pun sudah banyak tool-tool yang bersifat free yang kemampuannya sudah bisa dikatakan mumpuni untuk digunakan sebagai alat penyerangan oleh kalangan intruder dan attacker.

\section{METODE PENELITIAN}

Metode penelitian adalah cara dan langkah-langkah yang digunakan dalam melakukan penelitian. Pada penelitian dalam proses pengkajian data mining ini, cara dan langkah-langkah yang digunakan antara lain : Pengumpulan Data, Konsep Teori, dan Perancangan Sistem. Uraian metode penelitian yang digunakan dapat diuraikan sebagai berikut :

\subsection{Pengumpulan Data}

Dalam proses pengumpulan data, untuk mendapatkan data yang benar dan meyakinkan agar hasil yang dicapai tidak menyimpang dari tujuan yang telah diterapkan sebelumnya, penulis melakukan langkah langkph penelitian sebagai berikut :

1. Analisis

Metode ini gunanya untuk menganalisa sebuah rancangan yang telah dibangun, menganalisa proses dari penyerangan yang terjadi hingga mendapat pemeritahuan dalam bentuk $e$-mail.

2. Perancangan

Tahap ini akan meneterjemahkan spesifikasi kebutuhan yang telah didapat pada tahap analisis kedalam bentuk arsitektural perangkat lunak untuk di implementasikan kepada aplikasi yang dibuat

3. Pengujian

Dalam tahap pengujian dilakukan dengan menggunakan aplikasi untuk mendapatkan hasil pengujian yang sedang berjalan.

4. Dokumentasi

Pada proses dokumentasi, penulis juga melakukan studi pustaka, membaca dan mempelajari dokumen-dokumen, buku-buku acuan, serta sumber lainnya yang berkaitan dengan penelitian untuk dijadikan referensi.

\subsection{Dasar Teori}

Teori yang yang digunakan pada penelitian ini dapat diuraikan sebagai berikut :

\subsubsection{Router}

Router merupakan sebuah device atau alat yang dapat menghubungkan dua atau lebih jaringan komputer yang berbeda. Secara umum router adalah suatu alat pada jaringan komputer yang bekerja di networklayer pada lapisan OSI. Dalam Router ini terdapat routing table yaitu table yang berisi alamat-alamat jaringan yang dibutuhkan untuk memenuhi tujuan dari paket-paket data yang akan dilewatkan pada suatu jaringan tersebut.

Untuk membuat suatu router, kita dapat memanfaatkan suatu jenis operating system seperti operating systemWindows, Unix, Linux atau jenis operaring sistem lain pada komputer $P C$ kita dengan hanya menambahkan 2 buah Network Interface 
Card(NIC). Jika komputer kita sudah memiliki NIC misalnya $P C$ yang sudah onboard, maka kita cukup menambahkan 1 buah NIC lagi. Dengan bantuan implementasi dari router ini kita bisa membuat suatu jaringan $L A N$ dengan kelas yang berbeda-beda, misalnya kelas B dan Kelas C ataupun kelas lainnya.

\subsubsection{Firewall}

firewall adalah alat yang digunakan untuk mencegah orang luar untuk memperoleh akses ke suatu jaringan. Firewall pada umumnya merupakan suatu kombinasi dari perangkat lunak dan perangkat keras. Firewalls biasanya menerapkan pengeluaran rencana atau perintah untuk menyortir alamat yang tak dikehendaki dan diinginkan.[5]

Konfigurasi dari firewall bergantung kepada kebijaksanaan (policy) dari organisasi. Hal ini dapat dibagi menjadi dua bagian:

1. Apa-apa yang tidak diperbolehkan secara eksplisit dianggap tidak diperbolehkan (prohibitted)

2. Apa-apa yang tidak dilarang secara eksplisit dianggap diperbolehkan (permitted)

Firewall bekerja dengan mengamati packet IP (Internet Protocol) yang melewatinya. Berdasarkan konligurasi dari firewall maka akses dapat diatur berdasarkan IP address, port, dan arah informasi. Detail dari konfigurasi bergantung kepada masingmasing firewall. Untuk memahami bagaimana firewalls bekerja, Pengesahan pertama, paling sederhana memeriksa prosedur penggunaan $I P$ alamat sebagai suatu index. IP alamat index identifikasi universal pad internet . baik alamat statis maupun alamat yang dinamis.

IP alamat statis adalah alamat yang permanen yang merupakan alamat dari suatu mesin yang selalu dihubungkan ke Internet. Ada banyak kelas dari alamat IP statis. Satu kelas dapat ditemukan dengan query, kelas ini mesin tertinggi yang terhubung dengan jaringan, seperti domain dari server, Web server, dan root-level mesin. Yang sudah terdaftar sebagai hostnames pada databaseInterNIC. Kelas yang lain dari alamat IP statis adalah alamat yang ditugaskan kedua dan ketiga dari level mesin di dalam jaringan yang dikuasai oleh domain yang disebut server, root server, Web server, dan lainnya.

\subsubsection{Protocol}

protocol merupakan aturan-aturan dan prosedur untuk melakukan komunikasi. Ketika beberapa komputer dalam sebuah jaringan hendak melakukan komunikasi dengan komputer lain, aturan-aturan atau prosedur komunikasi harus dilakukan terlebih dahulu. Atuan-aturan tersebut dikenal dengan istilah protocol.

Beberapa hal yang perlu kita pahami tentang protocol dalam sebuah lingkungan jaringan komputer adalah sebagai berikut :

1. Dalam sistem jaringan komputer terdapat beberapa jenis protocol, masing-masing memiliki tujuan dan tugas yang berbeda. Setiap protocol memiliki kelebihan dan kekurangan.

2. Beberapa protocol dapat saling bekerjasama. Hal ini dikenal dengan istilah protocol stack atau protocol suite.

\subsubsection{Web Server}

web server adalah software yang menjadi tulang belakang dari world wide web (www) yang pertama kali tercipta sekitar tahun 1980an. Web server menunggu permintaan dari client yang menggunakan browser seperti Netscape Navigator, Internet Explorer, Mozilla Firefox, dan program browser lainnya. Jika ada permintaan dari browser, maka web server akan memproses permintaan itu kemudian memberikan hasil prosesnya berupa data yang diinginkan kembali ke browser.[6] 
Data ini mempunyai format yang standar, disebut dengan format SGML (Standar General Markup Language). Data yang berupa format ini kemudian akan ditampilkan oleh browser sesuai dengan kemampuan browser tersebut. Contohnya, bila data yang dikirim berupa gambar, browser yang hanya mampu menampilkan teks (misalnya lynx) tidak akan mampu menampilkan gambar tersebut, dan jika ada akan menampilkan alternatifnya saja.

Web server, untuk berkomunikasi dengan client-nya (web browser) mempunyai protokol sendiri, yaitu HTTP (hypertext transfer protocol). Dengan protokol ini, komunikasi antar web server dengan client-nya dapat saling dimengerti dan lebih mudah. Seperti telah dijelaskan diatas, format data pada world wide web adalah SGML. Tapi para pengguna internet saat ini lebih banyak menggunakan format HTML (hypertext markup language) karena penggunaannya lebih sederhana dan mudah dipelajari.

Standarisasi web server dalam penerapan penggunaannya antara lain dikeluarkan oleh W3C (World Wide Web Consortium), IETF (Internet Engineering Task Force), dan beberapa organisasi lainnya. Sampai saat ini, sudah lebih dari 110 spesifikasi yang dirilis oleh W3C (W3C Recommendations). [7]

Contoh standarisasi web server antara lain :

1. Spesifikasi HTML, CSS, DOM dan XHTML (W3C)

2. Spesifikasi Javascript (ECMA)

3. URL, HTTP (IETF) dalam bentuk dokumen RFC

\subsection{Snort}

Snort merupakan salah satu contoh program Network-based Intrusion Detection System, yaitu sebuah program yang dapat mendeteksi suatu usaha penyusupan pada suatu sistem jaringan komputer. Snort bersifat open source dengan lisensi GNU General Purpose License sehingga software ini dapat dipergunakan untuk mengamankan sistem server tanpa harus membayar biaya lisensi.[8][9][10]

Suatu sistem IDS harus bersifat lintas platform, mempunyai sistem footprinting yang ringan, dan mudah dikonfigurasi oleh administrator sebuah sistem yang membutuhkan implementasi dari solusi kemananan dalam waktu yang singkat. Implementasi tersebut dapat berupa seperangkat software yang dapat diasosiasikan dalam melakukan aksi untuk merespon sistuasi keamanan tertentu. Selain itu. sebuah sistem IDS juga harus powerfull dan cukup fleksibel untuk digunakan sebagai bagian permanen dari suatu sistem jaringan.

Snort memenuhi kriteria tersebut, yaitu dapat dikonfigurasi dan dibiarkan berjalan untuk periode yang lama tanpa meminta pengawasan atau perawatan bersifat administratif sebagai bagian dari sistem keamanan terpadu sebuah infrastruktur jaringan. Snort iuga dapat berjalan pada semua platform sistem operasi di mana libpcap dapat berjalan. Sampai saat ini, Snort telah teruji dapat berjalan pada sistem operasi RedHat Linux, Debian Linux, MkLinux, HP-UX, Solaris (x86 dan Sparc), $x 86$ Free/Net/OpenBSD, Windows dan MacOS X.

\section{2.6 Intrusion Prevention System}

Intrusion Prevention System (IPS) adalah pendekatan yang sering digunakan system keamanan komputer, IPS mengkombinasikan teknik firewall dan metode Intrusion Detection System (IDS) dengan sangat baik. Teknologi ini dapat digunakan untuk mencegah serangan yang akan masuk ke jaringan lokal dengan memeriksa dan mencatat semua paket semua paket dan serta mengenali paket dengan sensor, disaat attack telah teridentifikasi, IPS akan menolak akses (block) dan mencatat (log) semua paket data yang teridentifikasi tersebut. Jadi IPS bertindak seperti layaknya firewall yang akan melakukan 
allow dan block yang dikombinasikan seperti IDS yang dapat mendeteksi paket secara detail. IPS menggunakan signatures untuk mendeteksi di aktifitas trafik di jaringan dan terminal, dimana pendeteksian paket yang masuk dan keluar (inbound- outbound) dapat di cegah sedini mungkin sebelum merusak atau mendapatkan akses ke dalam jaringan lokal.[11][12]

\subsection{OSI (Open System Interconnection) Layer}

1. Phisycal Layer

lapisan ini bertanggung jawab untuk mengaktifkan dan mengatur physical interface jaringan komputer. Pada lapisan ini, hubungan antara interfaceinterface dari perangkat keras diatur seperti hubungan antara DTE dan DCE. Interface yang didefenisikan pada lapisan ini antara lain: 10BaseT, 100BaseTX, V35, X.21 dan High Speed S erial Interface (HSSI).[13][14]

2. Data Link Layer

Lapisan ini mengatur topologi jaringan, error notification dan flow control. Tugas utama datalink layer adalah sebagai fasilitas transmisi raw data dan mentransformasi data tersebut ke saluran yang bebas dari kesalahan transmisi.

Sebelum diteruskan ke network layer, data link layer melaksanakan tugas ini dengan memungkinkan pengirim memecah-mecah data input menjadi sejumlah data frame (biasanya berjumlah ratusan atau ribuan byte). Kemudian data link layer mentransmisikan frame tersebut secara berurutan, dan memproses acknowledgementframe yang dikirim kembali oleh penerima.[15]

3. Network Layer

Network layer berfungsi untuk pengendalian operasi subnet denganmeneruskan paket-paket dari satu node ke node lain dalam jaringan. Masalah desain yang penting adalah bagaimana caranya menentukan route pengiriman paket dari sumber ke tujuannya.

4. Transport Layer

Fungsi dasar transport layer adalah menerima data dari session layer, memecah data menjadi bagian-bagian yang lebih kecil bila perlu, meneruskan data ke network layer, dan menjamin bahwa semua potongan data tersebut bisa tiba di sisi lainnya dengan benar. Selain itu, semua hal tersebut harus dilaksanakan secara efisien, dan bertujuan dapat melindungi layer-layer bagian atas dari perubahan teknologi hardware yang tidak dapat dihindari.

5. Session Layer

Session layer mengijinkan para pengguna untuk menetapkan session dengan pengguna lainnya. Layer ini membuka, mengatur dan menutup suatu session antara aplikasi-aplikasi.

6. Presentation Layer

Presentation layer melakukan fungsi-fungsi tertentu yang diminta untuk menjamin penemuan sebuah penyelesaian umum bagi masalah tertentu. Selain memberikan sarana-sarana pelayanan untuk konversi, format dan enkripsi data, presentation layer juga bekerja dengan file berformat ASCII, EBCDIC, JPEG, MPEG, TIFF, PICT, MIDI, dan Quick Time. 
7. Application Layer

Lapisan ini bertugas memberikan sarana pelayanan langsung ke user, yang berupa aplikasi-aplikasi dan mengadakan komunikasi dari program ke program. Jika kita mencari suatu file dari file server untuk digunakan sebagai aplikasi pengolah kata, maka proses ini bekerja melalui layer ini. Demikian pula jika kita mengirimkan e-mail, browse ke internet, chatting, membuka telnet session, atau menjalankan FTP, maka semua proses tersebut dilaksanakan di layer ini.

\subsection{Flowchart}

Flowchart adalah penggambaran secara grafik dari langkah-langkah danurut-urutan prosedur dari suatu program. Flowchart menolong analis danprogrammer untuk memecahkan masalah kedalam segmen-segmen yang lebih kecil dan menolong dalam menganalisis alternatif-alternatif lain dalampengoperasian.Flowchart biasanya mempermudah penyelesaian suatu masalah khususnya masalah yang perlu dipelajari dan dievaluasi lebih lanjut.

\subsection{Perancangan Program}

Pada implemetasi jaringan dibawah ini terdapat $2 P C, P C 1$ berfungsi sebagai attacker dengan system operasi windows 7 ultimate. PC 2 berfungsi sebagai server dengan system operasi windows 7 ultimate dan winbox. Terdapat juga 1 router, 1 modem dan 1 smart phone untuk pemberitahuan serangan yang terjadi.

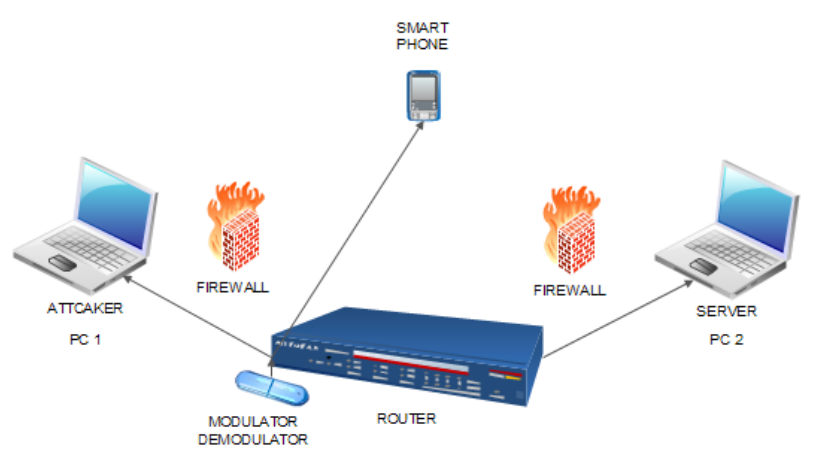

Gambar 1. Perancangan Intrusion Prevention system

Dari implementasi diatas dapat dilihat bahwa attacker akan mencoba menyerang ip server yang telah disediakan sebelumnya dengan memasukan username dan password yang tidak dikatahui oleh attacker kemudian server akan merespon serangan yang terjadi dan menyampaikan informasi ke smartphone dalam bentuk electronic mail (email). Tujuan pemberitahuan informasi melalui email adalah untuk mengantisipasi administrator yang tidak bisa selalu berada di depan server dimana modem yang tersedia telah disetting sebagai sumber internet yang dihubungkan ke router. Server juga akan mendapat informasi serangan yang terjadi karena sudah memliki layanan log sebagai pendeteksi serangan untuk memudahkan administrator yang berada didepan server.

\section{HASIL DAN PEMBAHASAN}

\subsection{Pengujian Setelah Menerapkan IPS pada Server}


Serangan berikut ini dilakukan setelah menerapkan sistem IPS pada Server Mikrotik. Dalam penelitian ini dilakukan uji coba penyerangan yaitu bruteforce, berikut adalah hasil uji coba dalam penelitian ini :

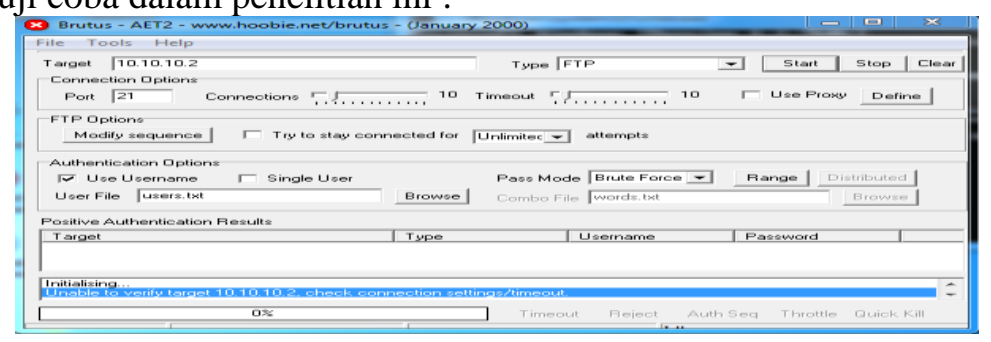

Gambar 2. Serangan Bruteforce dengan Brutus Berhasil Dicegah

Gambar 2 adalah proses serangan bruteforce yang dilakukan dengan menggunakan aplikasi brutus. Dalam proses penyusupan dan pembacaan username dan password, IPS telah mampu mencegah serangan yang terjadi dan dapat terlihat bahwa muncul pesan "Unable to verifity 10.10 .10 .2 , check connection setting/time out" yang menyatakan bahwa intruder mengalami timeout.

Serangan berikut ini dilakukan setelah menerapkan sistem IPS pada Server Mikrotik. Dalam penelitian ini dilakukan uji coba penyerangan yaitu bruteforcedengan pass mode $=$ word list , berikut adalah hasil uji coba dalam penelitian ini :

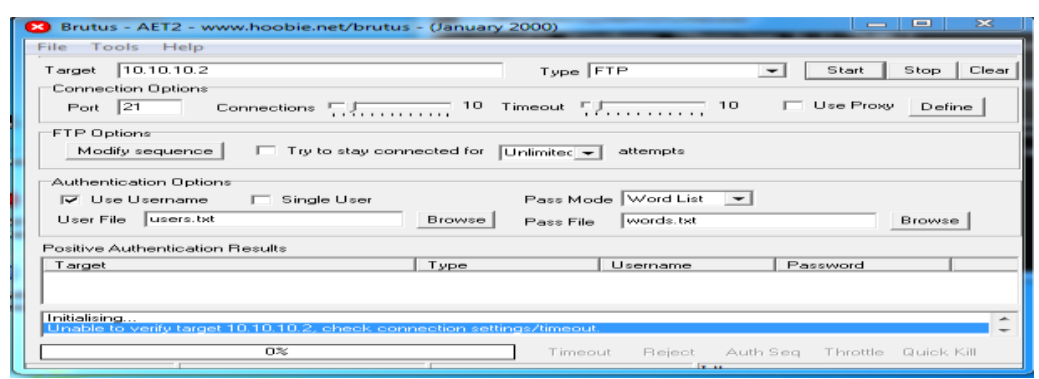

\section{Gambar 3. Serangan Bruteforce Pass Mode = Word List dengan Brutus Berhasil Dicegah}

Gambar 3 adalah proses serangan bruteforce dengan pass mode $=$ word list yang dilakukan dengan menggunakan aplikasi brutus. Dalam proses penyusupan dan pembacaan username dan password, IPS telah mampu mencegah serangan yang terjadi dan dapat terlihat bahwa muncul pesan "Unable to verifity 10.10.10.2, check connection setting/time out" yang menyatakan bahwa intruder mengalami timeout.

Serangan berikut ini dilakukan setelah menerapkan sistem IPS pada Server Mikrotik. Dalam penelitian ini dilakukan uji coba penyerangan yaitu bruteforcedengan pass mode $=$ combo list , berikut adalah hasil uji coba dalam penelitian ini

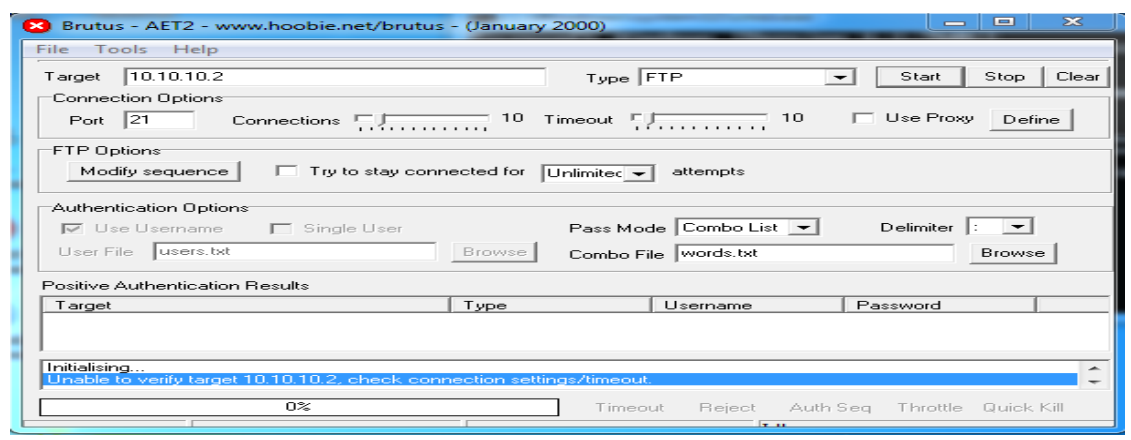




\section{Gambar 4. Serangan Bruteforce Pass Mode = Combo List dengan Brutus Berhasil Dicegah}

Gambar 4 adalah proses serangan bruteforce dengan pass mode $=$ combo list yang dilakukan dengan menggunakan aplikasi brutus. Dalam proses penyusupan dan pembacaan username dan password, IPS telah mampu mencegah serangan yang terjadi dan dapat terlihat bahwa muncul pesan "Unable to verifity 10.10.10.2, check connection setting/time out" yang menyatakan bahwa intruder mengalami timeout.

Serangan berikut ini dilakukan setelah menerapkan sistem IPS pada Server Mikrotik. Dalam penelitian ini dilakukan uji coba penyerangan yaituport scanning dengan Zenmap, berikut adalah hasil uji coba dalam penelitian ini :

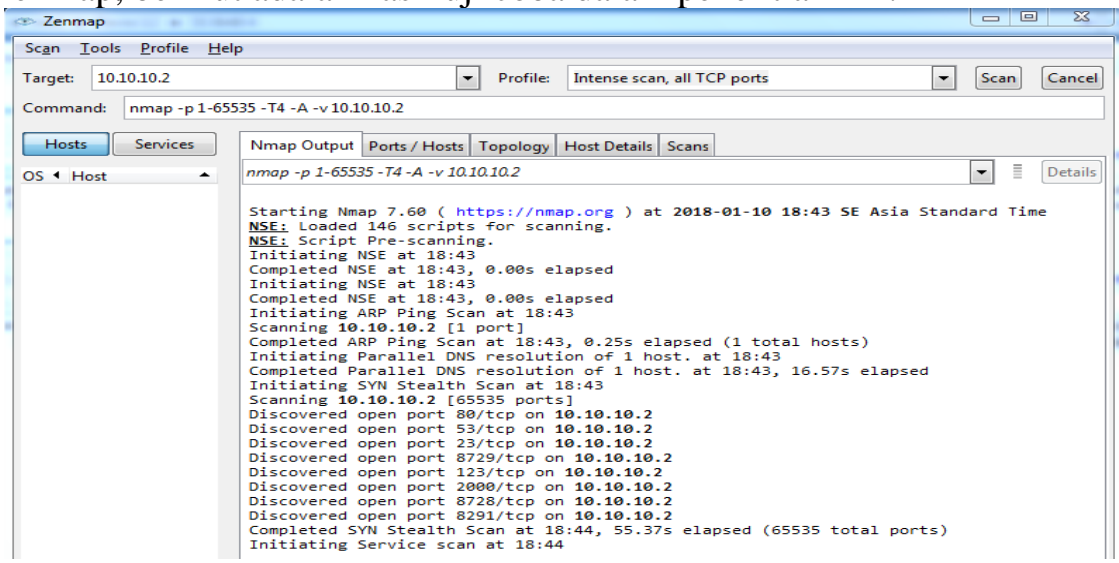

Gambar 5. Serangan Port Scanningdengan Nmap Berhasil Dicegah

Serangan PortScanning menggunakan zenmap pada client 1 dengan IP target 10.10.10.2, pada Gambar 5 memperlihatkan bahwa client 1 telah melakukan portscanning namun tidak bisa mendeteksi port 21 karena telah diterapkan IPS pada server mikrotik.

Serangan berikut ini dilakukan setelah menerapkan sistem IPS pada Server Mikrotik. Dalam penelitian ini dilakukan uji coba penyerangan yaituport scanning dengan Nmap pada windows 7, berikut adalah hasil uji coba dalam penelitian ini :

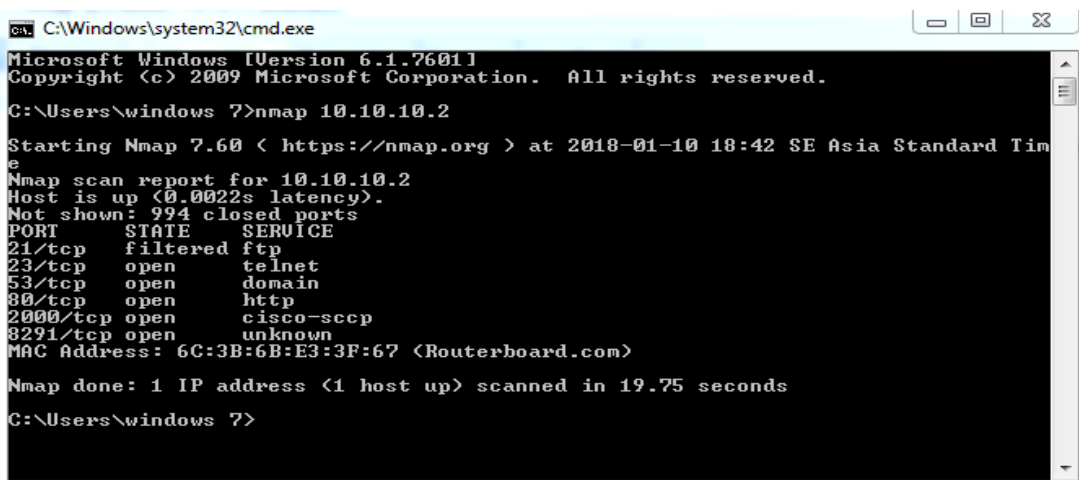

Gambar 6. Serangan Port Scanning dengan Nmap pada windows 7 berhasil dicegah

Serangan PortScanning menggunakan zenmap pada client 1 dengan IP target 10.10.10.2, pada Gambar 6 memperlihatkan bahwa client 1 telah melakukan portscanning dan berhasil dicegah oleh IPS pada server mikrotik. 
IT Journal Research and Development

Vol.3, No.1, Agustus 2018

e-ISSN: 2528-4053

DOI : 10.25299/itjrd.2018.vol3(1).1346

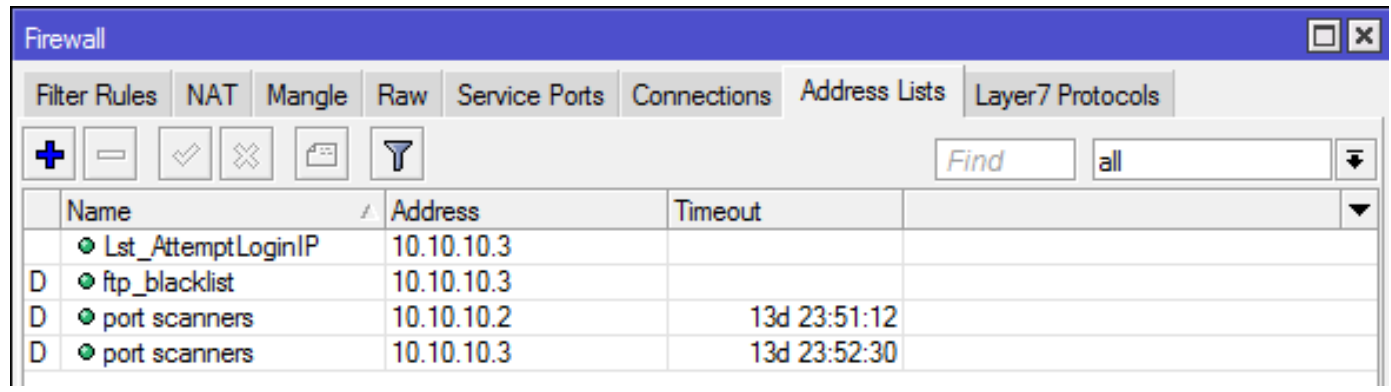

Gambar 7. Tampilan Address List Pada Firewall

Berikut adalah tampilan $\log$ mikrotik setelah penerapan IPS :

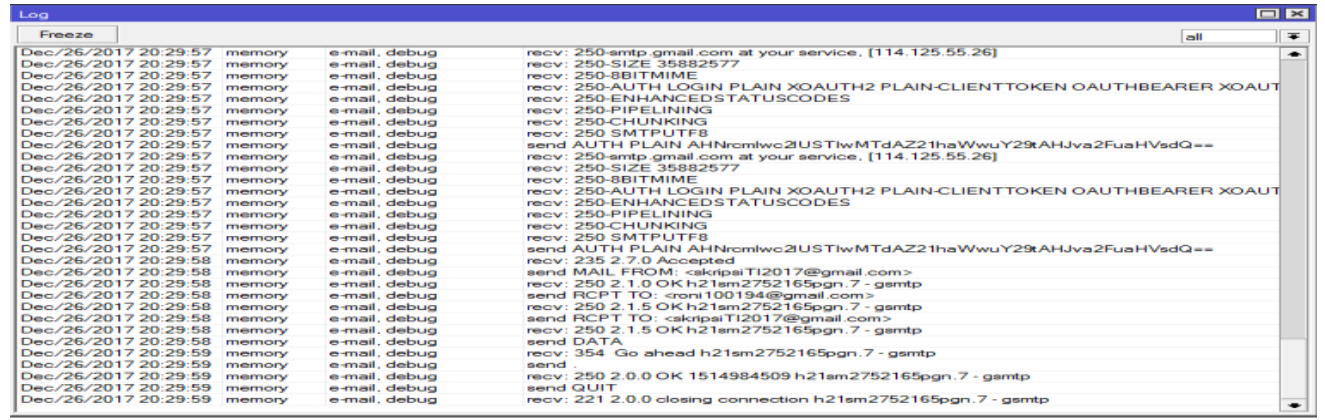

Gambar 8. Tampilan Log Mikrotik Setelah Penerapan IPS

Pada gambar 8 memperlihatkan log aktivitas yang terjadi dimana pada tanggal 26 Desember 2017 sudah tidak terjadi login failure for user admin from 10.10.10.3 via ftp. Berikut adalah tampilan filezilla dengan host 10.10.10.2, username admin dan password admin.

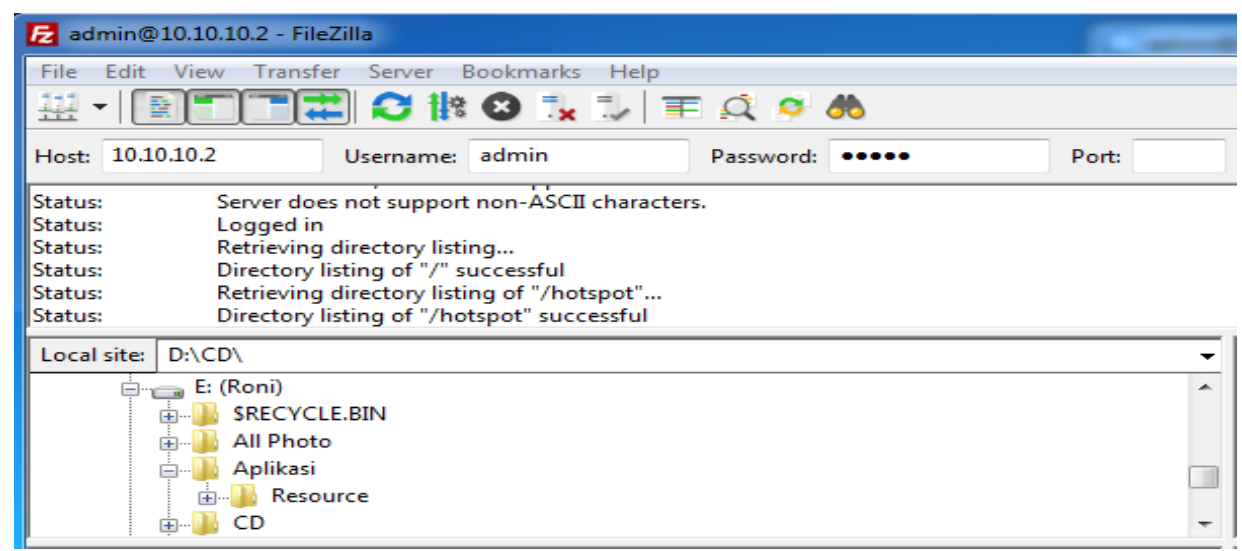

\section{Gambar 9. Tampilan Server FTPFilezilla}

Gambar 9 menunjukkan tampilan filezilla setelah connect ke host dan dapat dilihat directori E. Berikut adalah tabel perbandingan yang menjelaskan kondisi sebelum dan setelah penerapan IPS pada router mikrotik. 
Tabel 1. Perbandingan Sebelum dan Setelah Penerapan IPS

\begin{tabular}{|c|c|c|c|c|}
\hline Action & \multicolumn{2}{|c|}{ Sebelum Menerapkan IPS } & \multicolumn{2}{c|}{ Setelah Menerapkan IPS } \\
\hline Nama Aplikasi Penyerang & Zenmap & Brutus & Zenmap & Brutus \\
\hline Jenis Serangan & Port Scanning & Bruteforce & Port Scanning & Bruteforce \\
\hline Hasil Serangan & \multirow{2}{*}{ Port 21 Open } & Get Username = Admin & \multirow{2}{*}{ Port 21 Filtered } & \multirow{2}{*}{ Connection Timeout } \\
\cline { 3 - 5 } & - & Get Password = Admin & - & - \\
\hline Tampilan Log Mikrotik & - & Login Failure & - & - \\
\hline Email Pemberitahuan Serangan & - & Send To SkripsiTi2018@gmail.com & - & \\
\hline
\end{tabular}

Tabel 1 menjelaskan bahwa poin yang dibandingkan yaitu nama aplikasi penyerang, jenis serangan, hasil serangan, tampilan log mikrotik dan email pemberitahuan serangan.

\section{KESIMPULAN}

Berdasarkan hasil penelitian dan pembahasan yang telah diuraikan dalam penelitian yang Berjudul Simulasi Implementasi Intrusion Prevention system Pada Router Mikrotik maka dapat disimpulkan sebagai berikut :

1. Serangan atau penyusupan dapat dicegah dengan menerapkan Intusion Prevention System(IPS).

2. Serangan terdeteksi tergantung pada pola serangan yang ada didalam ruleIPS tersebut. Untuk itu pengelolaan filter rulespada perangkat IPS harus secara rutin melakukan pengembangan rules.

3. Serangan yang dilakukan dengan software brutus dalam bentuk bruteforce sudah bisa dicegah secara maksimal.

4. Serangan yang dilakukan dengan Nmap pada command prompt windows 7 dalam bentuk port scanningmasih belum bisa dicegah secara maksimal karena IPS masih membutuhkan beberapa kali serangan untuk bisa mendeteksi serangan dari ip yang sama.

5. Log mikrotik bekerja dengan maksimal untuk mendeteksi serangan yang terjadi.

\section{SARAN}

Dari pembahasan serta pengujian yang dilakukan tentunya terdapat hasil dan kendala selama proses pengerjaan maupun dari hasil yang diperoleh. Ada beberapa hal yang perlu dipertimbangkan untuk proses pengembangan selanjutnya yaitu:

1. Untuk pengembangan selanjutnya sebaiknya menggunakan lebih banyak aplikasi penyerangan agar rulesIPS yang diterapkan bisa bekerja lebih maksimal.

2. Sebaiknya menggunakan router board dengan versi yang lebih tinggi agar bekerja maksimal pada jaringan yang lebih luas.

3. Sebaiknya menambah rules serangan agar tidak hanya terbatas pada serangan bruterforce, contohnya rules serangan Dos. 


\section{DAFTAR PUSTAKA}

[1] Y. Arta, E. A. Kadir and D. Suryani, "KNOPPIX: Parallel computer design and results comparison speed analysis used AMDAHL theory," 2016 4th International Conference on Information and Communication Technology (ICoICT), Bandung, 2016, pp. 1-5. doi: 10.1109/ICoICT.2016.7571947

[2] Arta, Y. (2017). Implementasi Intrusion Detection System Pada Rule Based System Menggunakan Sniffer Mode Pada Jaringan Lokal. Information Technology Journal Research And Development, 2(1), 43-50.

[3] Novendra, Y., Arta, Y., \& Siswanto, A. (2018). Analisis Perbandingan Kinerja Routing OSPF Dan EIGRP. Information Technology Journal Research And Development, 2(2), 97-106.

[4] Arta, Y. (2017). Penerapan Metode Round Robin Pada Jaringan Multihoming Di Computer Cluster. Information Technology Journal Research And Development, 1(2), 26-35.

[5] Ariyus, Doni., 2006, Internet Firewall, Graha Ilmu, Yogyakarta

[6] Arifin, Zainal., 2005, Langkah Mudah Membangun Jaringan Komputer, Andi, Yogyakarta

[7] Nurmiati, Evy., 2012, Analisi dan Perancangan Web Server Pada Handphone Vol.5, No.2

[8] Affandi, Mohammad., Setyowibowo Sigit., 2013, Impelementasi Snort Sebagai Alat Pendeteksi Intrusi Menggunakan Linux Vol.4, No.2

[9] Kurniawan, Adhitya., Putri, Nabilla, Sayyidah., Hermanto, Dedy., 2016, Impelementasi Intrusion Prevention System (IPS) Menggunakan Snort, IP Tables, dan Honeypot pada Router Mikrotik.

[10] Towidjojo, Rendra., 2016, Mikrotik Kungfu, Jasakom.com

[11] Suhartono, Didit., Riyanto, Dwi, Andi., Astomo, Widy, Yogi., 2015., Intrusion Detection Prevention System (IDPS) Pada Local Area Network (LAN) Vol.8, No.1

[12] Ariyadi, Tamsir., Kunang, Novaria, Yesi., Santi Rusmala., 2012., Impelementasi Intrusion Prevention System (IPS) Pada Jaringan Komputer Kampus B Universitas Bina Darma

[13] Syafrizal, Melwin., 2017, 7 Layer Osi, Yogyakarta

[14] Yugianto, Gin-Gin, Rachman, Oscar., 2012, Router Teknologi, Konsep, Konfigurasi, dan Troubleshooting, INFORMATIKA, Bandung

[15] Syukur, A. (2018). Analisis Management Bandwidth Menggunakan Metode Per Connection Queue (PCQ) dengan Authentikasi RADIUS. IT Journal Research And Development, 2(2), 78 - 89. 